\title{
A Randomised, Crossover, Clinical Study to Assess Nicotine Pharmacokinetics and Subjective Effects of the BIDI Stick ENDS Compared with Combustible Cigarettes and a Comparator ENDS in Adult Smokers
}

lan M. Fearon ( $\square$ ian@whatifconsulting.net)

whatIF? Consulting Ltd

Karin Gilligan

McKinney Regulatory Science Advisors, LLC

Ryan G.N. Seltzer

Safety in Numbers

Willie McKinney

McKinney Regulatory Science Advisors, LLC

\section{Research Article}

Keywords: Nicotine, pharmacokinetics, subjective effects, electronic nicotine delivery system, cigarette, smoking

Posted Date: November 24th, 2021

DOI: https://doi.org/10.21203/rs.3.rs-1106788/v1

License: (c) (1) This work is licensed under a Creative Commons Attribution 4.0 International License. Read Full License 


\section{Abstract}

Background: Nicotine pharmacokinetic assessments of electronic nicotine delivery systems (ENDS) are crucial to understand their ability to provide an alternative to cigarette smoking. Subjective effects data also strongly contribute to this understanding. The BIDI® Stick is a disposable ENDS product which contains $6 \%$ nicotine benzoate salt and various flavours.

Methods: In this study we assessed nicotine pharmacokinetic and subjective effects of BIDIß Stick ENDS in adult smokers, compared to cigarettes and a comparator ENDS product. During each of eight (8) study visits, volunteer smoker subjects randomly used one of either their usual brand (UB) of cigarette, a BIDI® Stick ENDS, or a comparator ENDS (JUUL 5\% with Virginia Tobacco flavour), during both defined (10 puffs, 30 seconds apart) and ad libitum puffing sessions. Blood samples were collected at various time points and subjective effects questionnaires were administered.

Results: Plasma nicotine Cmax 0-120 was not significantly different between BIDIß Stick ENDS with any flavour (range $15.3(9.90) \mathrm{ng} / \mathrm{ml}$ for BIDI® Stick Winter to 17.6 (9.00) ng/ml for BIDI® Stick Classic) and UB cigarettes [16.2 (9.17) ng/ml]. AUC0-120 and Tmax 0-120 values were also not significantly different between BIDI® Stick ENDS and UB cigarettes, while subjective effects measures were also similar between BIDI® Stick ENDS and UB cigarettes.

Conclusions: BIDI® Stick ENDS delivered nicotine to users comparably to their UB combustible cigarette and also elicited similar subjective effects such as satisfaction and relief. Thus, the BIDIß Stick ENDS may be a satisfying alternative to cigarettes among current smokers and may support their transitioning away from cigarette smoking.

Trial registration: ClinicalTrials.gov (identifier number NCT05072925).

\section{Background}

Cigarette smoking is the leading preventable cause of morbidity and mortality worldwide, and is the primary causative factor in the deaths of more than 7 million smokers annually [1]. A number of serious human disorders are caused by cigarette smoking, including heart disease, lung disease and lung cancer, which arise due to a smokers' inhalation of toxic chemicals formed during the combustion of tobacco [2-4]. Cigarette smoke contains approximately 6,500 identified chemicals [3], and a number of these chemicals have a demonstrated association with the development of specific smoking-related diseases [5]. For smokers, the best possible means of reducing the risk to their health is to quit smoking [6], and large numbers of adult smokers report such a desire to stop smoking. However, the addictive nature of cigarette smoking means that quitting smoking is inherently difficult. Unfortunately, less than $10 \%$ of adult smokers actually manage to stop smoking annually [7].

Alternative forms of nicotine delivery that satisfy a smokers' desire for nicotine and reduce or eliminate exposure to tar and harmful toxicants found in cigarette smoke have been suggested since the 1970s as a means to reduce smokingrelated health risks [8]. Regarding smokers who are either unable or unwilling to quit smoking, a number of public health bodies, such as Public Health England, the UK Royal College of Physicians, the New Zealand Ministry of Health and Health Canada, proposed that reduced-exposure products may provide a less harmful alternative to combustible cigarettes and support efforts to reduce the global burden of cigarette smoking [9-11]. E-cigarettes, also known as an Electronic Nicotine Delivery Systems (ENDS), generate an aerosol via electrical heating of an e-liquid that most commonly contains nicotine $[12,13]$. Since the heating temperature required to aerosolise e-liquids is much lower than the smoke-producing temperature developed during the combustion of tobacco leaves in conventional cigarettes, ENDS aerosols contain far fewer and substantially lower levels of harmful toxicants compared with cigarette smoke 
[14-16]. Therefore, exposure to cigarette smoke toxicants is either greatly reduced or absent in smokers who completely switch to ENDS [17-22]. In many instances, biomarkers of exposure are at levels seen with smoking abstinence $[17,19]$ or in non-smokers. This exposure reduction has the potential to reduce the risk of tobacco-related disease in smokers who completely switch to using ENDS. Consequently, some public health bodies, including Public Health England, have proposed the use of ENDS as a potentially reduced-harm alternative to cigarette smoking for adult smokers [9], and particularly those who have been unable to quit by other means. Furthermore, a growing body of literature indicates that ENDS have the potential to support smoking cessation [23], particularly in those who use ENDS daily and non-intermittently $[24,25]$.

It has been suggested that ENDS nicotine delivery is an important factor in determining their ability to facilitate smokers' switching away from cigarette smoking [26-28]. For example, nicotine-containing smoking cessation products such as nicotine gum that have higher nicotine content, deliver greater amounts of nicotine to users and produce greater satisfying and reinforcing effects are more effective in promoting smoking cessation [26, 29-31], particularly among highly-dependent smokers $[26,32,33]$. Furthermore, greater nicotine delivery from ENDS is associated with greater reductions in urges to smoke as well as other beneficial subjective effects such as greater satisfaction, liking and reductions in withdrawal symptoms [34], as well as greater reductions in exposure to cigarette smoke toxicants $[35,36]$.

The BIDI ${ }^{\circledR}$ Stick is a disposable ENDS that contains an e-liquid with $6 \%$ nicotine in the form of a nicotine benzoate salt and a variety of flavours, which has been marketed in the United States as an alternative to cigarette smoking for adult smokers since 2014. While the nicotine pharmacokinetic profile of various types of ENDS products have been reported in the literature [13,37, 38], including disposable ENDS [39], no studies have yet examined nicotine pharmacokinetics for disposable ENDS with a high concentration of nicotine salt in the e-liquid. In this paper, we describe findings from a clinical study assessing nicotine pharmacokinetics and subjective effects of the BIDI ${ }^{\circledR}$ Stick ENDS with various flavours, compared to combustible cigarettes and a comparator pod-based (JUUL) ENDS.

\section{Methods}

This study was an open-label, randomised, crossover, clinical study in which healthy adult smokers were assigned to use one of eight (8) investigational products at each clinic visit and according to a pre-determined randomisation schedule. The study was conducted in July and August 2021 at the facilities of MTZ Clinical Research Sp. Z.o.o., Warsaw, Poland, in accordance with the principles of International Conference on Harmonisation Harmonised Tripartite Guideline for Good Clinical Practice (GCP) and the Declaration of Helsinki. GCP compliance was assured by both a pre-study GCP audit by an independent auditor and by frequent monitoring visits during study conduct by an independent Clinical Research Associate. Ethics approval was received from the Ethics Committee of the District Medical Board in Warsaw (Resolution 15/21, 29 ${ }^{\text {th }}$ April 2021). All subjects received financial remuneration for their participation in the study, which was approved by the ethics committee. The study was registered on the ClinicalTrials.gov repository (identifier number NCT05072925).

\section{Subjects}

Subjects were adults aged 21-65 years inclusive and were current smokers of at least 10 factory-manufactured cigarettes a day with a Federal Trade Commission tar yield of $8-10 \mathrm{mg}$, had been smoking cigarettes for at least 12 months, and may have been dual users of ENDS. At a screening visit, which took place no more than 28 days before the first study visit, potential subjects provided written consent on an ethics committee-approved informed consent form. At this visit, a review of the potential subjects' medical history, a physical examination, clinical laboratory 
assessments, an electrocardiogram (ECG), vital signs measurements, a urine pregnancy test (female subjects only) and a chest X-ray were performed to ensure that potential subjects were healthy. Urinary cotinine $(\geq 200 \mathrm{ng} / \mathrm{mL}) \mathrm{and}$ exhaled carbon monoxide (eCO; > 10ppm) were also assessed to confirm cigarette smoking status and a urine screen for drugs of abuse was performed. Subjects' cigarette smoking and nicotine product use history was captured, and the Fagerstrom Test for Cigarette Dependence (FTCD) [40] was administered.

Female subjects were ineligible if they were pregnant or breastfeeding and were required to practice a reliable method of contraception for the duration of the study. Exclusion criteria also included any clinically relevant medical or psychiatric disorder, abnormal findings in the physical examination, clinical laboratory assessments, ECG or chest X-ray, or a positive screen for drugs of abuse. Potential subjects who had a positive text for SARS-CoV-2 (COVID-19) or displayed any symptoms indicative of active SARS-CoV-2 infection were also excluded from the study.

\section{Study Products}

Six BIDI ${ }^{\circledR}$ Stick ENDS, each containing $6 \%$ nicotine benzoate salt and different flavours, were assessed in the study. The specific products assessed were BIDI ${ }^{\circledR}$ Stick Arctic, Classic, Zest, Regal, Winter and Solar. A comparator ENDS product, the JUUL pod system ENDS with $5 \%$ nicotine benzoate salt and Virginia Tobacco flavour, was also assessed. All subjects provided their usual brand (UB) of combustible cigarette for use as a reference cigarette.

\section{Randomisation procedure}

Randomisation sequences were prepared by MTZ Clinical Research Sp. z.o.o. and were produced using a block randomisation (Williams) procedure (18 subjects randomised to the 14 treatment sequences, size of block equal to 1) for 7 treatments in 7 periods (i.e., generation of a Latin-square design, where every treatment followed every other treatment the same number of times). Equal allocation of subjects to each sequence was ensured.

\section{Study Procedures}

At screening, subjects underwent numerous assessments outlined above to assure their health status. Subjects who passed all screening assessments and provided written informed consent visited the clinic site on eight (8) separate occasions, with each clinic visit separated by at least two (2) days. At the first of these visits, subjects underwent nicotine pharmacokinetic and subjective effects assessments with their usual brand (UB) of combustible cigarette. Prior to each subsequent visit, subjects were provided with a supply of either the BIDI ${ }^{\circledR}$ Stick ENDS or the JUUL ENDS they were to use at their next clinic visit according to the randomisation schedule, to use at home for a familiarisation period of at least two (2) days. At each clinic visit, subjects used their randomly assigned product and underwent nicotine pharmacokinetic and subjective effects assessments. Prior to each clinic visit subjects were instructed to abstain from the use of any nicotine-containing products for a period of at least 12 hours. Compliance with this instruction was assessed by measuring eCO with a cut-off level of $15 \mathrm{ppm}$. After the final clinic visit, subjects were discharged from the clinic after all nicotine pharmacokinetic and subjective effects assessments were completed. Subjects were contacted by telephone no longer than one (1) week after the final study visit to capture any post-study adverse events (AEs).

\section{Nicotine Pharmacokinetics}

During the first clinic visit (Visit 2), subjects smoked their UB combustible cigarette during two (2) use sessions. In the first session, subjects smoked a single combustible cigarette by taking 10 puffs with each puff 30 seconds apart (controlled puffing). Blood samples (4 mL) were obtained for plasma nicotine analysis at $-5,3,5,7,10,15,30,45,60$, 75 , and 120 minutes relative to the first puff on the cigarette. In the second session, which began immediately after the 
last (120 minute) blood draw, subjects were allowed to take ad libitum puffs on their UB cigarette for a period of 60 minutes. During this ad libitum session, subjects were allowed smoke as many cigarettes as they liked. A blood sample for nicotine pharmacokinetic analysis was drawn at the end of the session (i.e., at 180 minutes). At subsequent visits, subjects used their assigned ENDS product following the same procedures.

Blood samples $(4 \mathrm{ml})$ for plasma nicotine analysis were drawn into dipotassium ethylenediaminetetraacetic acid $\left(\mathrm{K}_{2}\right.$ EDTA) vacutainer tubes via an intravenous catheter port. No later than 90 minutes after collection, samples were centrifuged at $1500 \mathrm{RPM}$ at $4^{\circ} \mathrm{C}$ for 10 minutes. The plasma fraction was transferred to two (2) sterile polypropylene screw cap tubes and stored frozen at $-20^{\circ} \mathrm{C}$ within 120 minutes of collection. Plasma samples were shipped on dry ice to a commercial bioanalytical laboratory (Altasciences Company Inc., Laval, Quebec, Canada). Nicotine levels were assessed with a validated reversed-phase HPLC with MS/MS method, using an AB Sciex API 5000 quadrupole mass spectrometer and a Turbo $\mathrm{V}$ ion source with ES probe and operating in positive ion mode. The lower limit of quantification (LLOQ) for this assay was $0.200 \mathrm{ng} / \mathrm{ml}$, and the upper limit of quantification (ULOQ) was 100.000 $\mathrm{ng} / \mathrm{ml}$.

\section{Subjective Effects Assessments}

At the end of the ad libitum puffing session, subjects completed the 21-item Product Evaluation Scale (PES) [41] for which responses were recorded on a 7-point Likert scale ranging from 'Not at all' to 'Extremely'.

\section{Statistical Analyses}

Since this study was the first to examine nicotine pharmacokinetics in subjects using BIDI ${ }^{\circledR}$ Stick ENDS, no formal power calculations were performed. The sample size is typical of other studies reported in literature examining the pharmacokinetics and subjective effects of different tobacco/nicotine products [37] and a sample size of 18 subjects was determined adequate to meet the study objectives.

Descriptive statistics for pharmacokinetic parameters, including baseline-adjusted maximum plasma nicotine concentration between 0 and 120 minutes $\left(C_{\max 0-120}\right)$; time to maximum plasma nicotine concentration following defined puffing ( $T_{\max }$ 0-120); and baseline-adjusted area under the plasma nicotine concentration-time curve at 120 minutes $\left(\mathrm{AUC}_{0-120}\right)$ were summarised for each study product. $\mathrm{AUC}_{0-120}$ was calculated using a linear trapezoidal method. Following baseline adjustment, any $A_{U C} C_{0-120}$ values which fell below zero were excluded from both descriptive and inferential statistics.

For inferential statistical analyses, linear mixed models were used to test differences in log-transformed $\mathrm{C}_{\text {max } 0-120}$ and $\mathrm{AUC}_{0-120}$ values between BIDI ${ }^{\circledR}$ Stick ENDS, JUUL, and UB cigarettes. Subject was included as a random effect. The sequence of product used was initially specified as a random effect, but the models produced non-positive definite $\mathrm{G}$ matrices and so this variable was removed as a random effect. Model parameter estimates were exponentiated back to their original scale and used to create $90 \%$ confidence intervals for the ratio of geometric, least-squares means. Statistically significant differences between test products were determined if the $90 \%$ confidence interval range did not include the value 1.00. Proportional odds generalised linear mixed models were used to test differences in $T_{\max }$ values between $B I D I^{\circledR}$ Stick ENDS, JUUL, and UB cigarettes. The subject and sequence order of the product used were specified as random effects. Statistical significance was determined for $90 \%$ odds ratio confidence intervals that did not contain the value 1.00 .

The PES was analysed by assessing four composite subscales: (1) "satisfaction"; (2) "psychological reward"; (3) "aversion"; and (4) "relief" [41]. PES subscale scores were summarised using descriptive statistics for each study 
product and post-hoc pairwise comparisons between study products were made using linear mixed effects models with the subject specified as a random effect.

Statistical analyses were performed using SAS Version 9.4 (Cary, NC, USA) with alpha = 0.05 (2-tailed).

\section{Safety Assessments}

Safety and tolerability were assessed by collecting information concerning the incidence, nature and severity of any AEs experienced by subjects. Vital signs (blood pressure and heart rate) were also routinely monitored during study visits.

\section{Results}

\section{Study Population}

Of 41 subjects who were screened, 18 (43.9\%) met all of the inclusion criteria and none of the exclusion criteria and were enrolled into the study. Seventeen subjects attended the clinical site for all eight (8) study visits and used their randomly assigned study product in the product use sessions; one subject was discontinued after Visit 2 (UB cigarette smoking) due to a number of adverse events (headache, nausea, coughing) which occurred following the nicotine pharmacokinetic session. Brief demographic details of the 18 subjects are provided in Supplementary Table 1.

Subjects' mean (SD) age was 39.2 (9.21) years, approximately two-thirds were male, and all were of Caucasian race. On average, subjects FTCD score was 5.8 (1.66) and subjects usually smoked on average 15.8 (3.56) cigarettes per day and had been smoking for an average of 19.3 (7.66) years. Two subjects had prior experience of ENDS use, but neither these nor any other subjects were currently using ENDS.

\section{Nicotine Pharmacokinetics}

During use of all study products in the controlled puffing session, plasma nicotine levels rose rapidly (Figure 1). The mean (SD) maximum plasma nicotine concentration reached following this session $\left(C_{\max 0-120}\right)$ was $16.2(9.17) \mathrm{ng} / \mathrm{ml}$ for subjects' UB combustible cigarette (Table 1). $C_{\max 0-120}$ values were not significantly different (Tables 1 and 2) for each of the BIDI ${ }^{\circledR}$ Stick ENDS assessed compared both each other and with UB cigarettes and ranged from 15.3 (9.90) $\mathrm{ng} / \mathrm{ml}$ for BIDI ${ }^{\circledR}$ Stick Winter to $17.6(9.00) \mathrm{ng} / \mathrm{ml}$ for BIDI ${ }^{\circledR}$ Stick Classic. $\mathrm{C}_{\text {max } 0-120}$ for the comparator ENDS product (JUUL Virginia Tobacco) was $6.8(4.13) \mathrm{ng} / \mathrm{ml}$, which was significantly lower than that for either the UB cigarettes or any of the $\mathrm{BIDI}^{\circledR}$ Stick ENDS (Table 2). Similar to $\mathrm{C}_{\max 0-120}$, area under the plasma nicotine concentration-time curve between 0 and 120 minutes $\left(\mathrm{AUC}_{0-120}\right)$ values for any of the BIDI ${ }^{\circledR}$ Stick ENDS were not significantly different than that for UB cigarettes, while $A_{U} C_{0-120}$ for the comparator (JUUL) ENDS product was significantly lower than that for both the UB cigarettes and any of the BIDI ${ }^{\circledR}$ Stick ENDS (Tables 1 and 2). Time to maximum plasma nicotine concentration values for the defined puffing session ( $T_{\max 0-120}$ ) ranged from 6.0 minutes for both the BIDI ${ }^{\circledR}$ Stick Regal and Winter ENDS (SDs 1.58 and 1.41, respectively) to 6.7 (2.74) minutes for the UB cigarettes (Table 1). T max 0-120 for the JUUL comparator ENDS was 5.9 (1.73) minutes. There were no statistically significant differences in $T_{\max } 0-120$ between any of the study products.

During the ad libitum use session, plasma nicotine levels rose again for all study products (Figure 1). While no formal statistical analysis was performed, $\mathrm{C}_{\max 120-180}$ was highest for $\mathrm{BIDI}^{\circledR}$ Stick Arctic ENDS and lowest for UB cigarettes and JUUL Virginia Tobacco (Figure 1 and Table 1). 


\section{Subjective Effects}

Analysis of the composite scores for the PES "relief", "satisfaction" and "aversion" subscales showed no statistically significant differences between any of the study products (Table 3). For the 'psychological reward' subscale, a significant difference between study products was observed only between subject's UB cigarette and the BIDI ${ }^{\circledR}$ Stick Winter ENDS. The individual item "was it enough nicotine" item, which is a component of the "relief" subscale was assessed individually. Mean score for this item were highest for the UB cigarette and lowest for JUUL Virginia Tobacco ENDS (Table 3). UB cigarette was significantly higher than BIDI ${ }^{\circledR}$ Stick Arctic and JUUL Virginia Tobacco, while the JUUL ENDS was significantly lower than BIDI ${ }^{\circledR}$ Stick Regal, Solar and Zest.

\section{Safety Assessments}

No serious adverse events occurred during the study. A small number of adverse events occurred in some subjects, including headaches, dizziness and events related to blood draws (e.g., bruising). These were all classed as either mild or moderate and quickly resolved without treatment.

\section{Discussion}

The primary finding from this clinical study was that the BIDI ${ }^{\circledR}$ Stick ENDS delivered nicotine to users in a manner comparable to that from subject's UB combustible cigarette. In terms of $C_{\text {max }}$ AUC and $T_{\text {max }}$, these parameters were not significantly different for any flavour of $B I D I^{\circledR}$ Stick ENDS compared to the combustible cigarette. Such a finding is unique in the literature for a disposable e-cigarette, although refillable tank-type ENDS devices and pod-based ecigarettes have been found to deliver nicotine in a manner similar to [12,13,27, 28] or exceeding [42] that from combustible cigarettes. It has been proposed that providing sufficient nicotine delivery with either a greatly reduced, or absence of, exposure to harmful toxicants would be tolerated by smokers and thus may better serve tobacco harmreduction efforts by shifting smokers down the continuum of risk towards a less harmful tobacco product $[8,10]$ or helping them to stop smoking [27]. Furthermore, it has been acknowledged by the U.S. Food and Drug Administration that cigarette-like nicotine delivery from the heated tobacco product IQOS is potentially beneficial to smokers trying to switch since they are more likely to completely switch away from and not resume combustible cigarette smoking [10, 43], while a recent study concluded that an ENDS was most likely to help smokers reduce toxicant exposure and cigarette consumption when it was capable of delivering nicotine at levels similar to that of a cigarette [35]. In addition, it was proposed following a comparison of the nicotine delivery between U.S. and European versions of the JUUL ENDS that since nicotine delivery from the European version was not as effective it may have more limited potential in helping smokers stop smoking [28]. Effective nicotine delivery from non-inhaled smoking cessation products is also suggested to provided better assistance in smoking cessation [26, 30-33] . Overall therefore, our finding of comparability between nicotine delivery from BIDI ${ }^{\circledR}$ Stick ENDS and combustible cigarettes supports that the $\mathrm{BIDI}^{\circledR}$ Stick ENDS may facilitate smokers switching to a form of nicotine intake with reduced exposure to harmful toxicants.

It has been suggested that high nicotine delivery from ENDS may be harmful if it leads to greater dependence [42], although a recent study [44] reported no differences in dependence between users of low, medium and high strength nicotine e-liquids in either pod-based or disposable ENDS which presumably give rise to different nicotine exposures. Furthermore, from our nicotine pharmacokinetic and subjective effects findings it is unlikely that dependence on BIDI ${ }^{\circledR}$ Stick ENDS would be greater than that of combustible cigarettes, and this is supported by the literature which suggests lower dependence on ENDS compared to cigarettes [45], although that analysis did not take e-liquid nicotine concentration into account and likely arose from an analysis of users of a diverse range of nicotine concentrations. A 
recent study also examined dependence among smokers who switched to using the JUUL ENDS, demonstrating no difference in dependence between $3 \%$ and $5 \%$ nicotine concentrations, as well as demonstrating that regardless of nicotine concentration used, dependence on JUUL use was lower than dependence on cigarette smoking [17]. While it is unlikely therefore that dependence on using $\mathrm{BIDI}^{\circledR}$ Stick ENDS would be higher than dependence on cigarette smoking, and may in fact be lower, this requires further assessment.

An interesting facet of our analyses of pharmacokinetic data is the finding of no difference in nicotine pharmacokinetics between BIDI ${ }^{\circledR}$ Stick ENDS containing different flavours. A small number of studies have assessed the impact of ENDS flavours on nicotine pharmacokinetics; one study reported an impact of flavours on $\mathrm{C}_{\max }$ although the data appeared skewed by an abnormally high $\mathrm{C}_{\max }$ for a cherry flavour which was likely due to the cherry e-liquid having a lower $\mathrm{pH}$ than the other liquids and much smaller differences were seen between other flavours with a similar $\mathrm{pH}$ [46], a small impact of certain flavours [46-48], or no impact $[49,50]$. Our study data show that a comprehensive range of flavoured $B I D I^{\circledR}$ Stick ENDS do not differentially impact nicotine pharmacokinetics or abuse liability/dependence measures when compared to tobacco flavoured BIDI ${ }^{\circledR}$ Stick ENDS.

In addition to comparable nicotine delivery to cigarettes, we observed comparable subjective effects following the use of $\mathrm{BIDI}^{\circledR}$ Sticks ENDS. Plasma nicotine $\mathrm{C}_{\max }$ in ENDS users correlates with satisfaction [34], while other subjective effects related to ENDS use are better indicators of the potential for ENDS to act as a viable alternative to cigarette smoking $[51,52]$. This is likely of great importance when considering the harm reduction potential of ENDS. In this regard, a multidimensional framework for nicotine-containing products has been developed [51] which takes into account toxicity/harmfulness, appeal and dependence. Using this framework, it has been suggested that the "sweet spot" for a nicotine product occurs when appeal and dependence are maximised and toxicity/harmfulness are minimised. Several studies have demonstrated reduced toxicant levels in ENDS emissions compared to cigarette smoke $[9,14-16]$. In line with these findings, emissions testing of BIDI ${ }^{\circledR}$ Stick ENDS demonstrated toxicant levels which were both significantly less than those in cigarette smoke and comparable to emissions from other ENDS (data not shown). This supports a profile of lower toxicity and harmfulness of using BIDI ${ }^{\circledR}$ Stick ENDS compared with cigarette smoking. Given this potential lower toxicity, along with evidence of comparable abuse liability/dependence potential of the BIDI ${ }^{\circledR}$ Stick ENDS (based on nicotine delivery and subjective effects) and comparable appeal of the BIDI ${ }^{\circledR}$ Stick ENDS (based on subjective effects findings), this suggests that the BIDI ${ }^{\circledR}$ Stick ENDS has an appropriate balance of toxicity, appeal and dependence and is a viable alternative to cigarette smoking. BIDI ${ }^{\circledR}$ Stick ENDS therefore will likely have a positive impact on net population health [51].

Interpretation of the findings from this study may be subject to some limitations. Firstly, the study was conducted in a cohort of smokers in Poland, whereas BIDI ${ }^{\circledR}$ Stick ENDS are currently only marketed in the U.S. Thus, our nicotine pharmacokinetic and subjective effects data may not reflect those of a U.S. smoker using BIDI ${ }^{\circledR}$ Stick ENDS. However, this limitation is mitigated by the study inclusion criteria, which ensured that only smokers of high-yield cigarettes were eligible for entry into the study, and this approach was taken to more closely match the higher yield cigarettes more commonly smoked by US smokers $[53,54]$. Furthermore, in the study a comparator ENDS (JUUL Virginia Tobacco) was included and our nicotine pharmacokinetic findings for both combustible cigarettes and JUUL Virginia Tobacco closely match those previously reported in similar studies in U.S. smokers $[47,55]$. Secondly, while our studies included a period in which study subjects were allowed to use the study products prior to their nicotine pharmacokinetic and subjective effects assessments, this period was short. It has been described that nicotine delivery from ENDS may change over time as users become acclimatised to the devices [36,56,57], and therefore, our findings may not reflect nicotine delivery in an acclimatised BIDI ${ }^{\circledR}$ Stick ENDS user. 


\section{Conclusions}

In summary, nicotine pharmacokinetic assessments showed that the BIDI ${ }^{\circledR}$ Stick ENDS delivered nicotine to users in a manner comparable to their UB combustible cigarette. Subjective effects data, including satisfaction and relief were also comparable between cigarette and BIDI ${ }^{\circledR}$ Stick ENDS. These findings support the BIDI ${ }^{\circledR}$ Stick ENDS as a satisfying alternative for current smokers and may support their transitioning away from harmful cigarette smoking.

\section{Abbreviations}

\begin{tabular}{|ll|}
\hline Abbreviation & Meaning \\
\hline AE & Adverse event \\
\hline CI & Area under the plasma nicotine concentration-time curve \\
\hline C $_{\text {max }}$ & Confidence interval \\
\hline ECG & Maximum plasma nicotine concentration \\
\hline eCO & Electrocardiogram \\
\hline ENDS & Exhaled carbon monoxide \\
\hline FTCD & Fagerstrom Test for Cigarette Dependence \\
\hline GCP & Good Clinical Practice \\
\hline HPLC & High-performance liquid chromatography \\
\hline K 2 EDTA & dipotassium ethylenediaminetetraacetic acid \\
\hline LLOQ & Lower limit of quantification \\
\hline PES & Product Evaluation Scale \\
\hline RPM & Revolutions per minute \\
\hline SD & Standard deviation \\
\hline T max & Time of maximum plasma nicotine concentration \\
\hline UB & Unper limit of quantification \\
\hline UK & \\
\hline ULOQ & Usuand (of combustible cigarette) \\
\hline
\end{tabular}

\section{Declarations}

\section{Ethics approval and consent to participate}

Ethics approval was received from the Ethics Committee of the District Medical Board in Warsaw (Resolution 15/21, $29^{\text {th }}$ April 2021). All subjects provided written informed consent on an ethics committee-approved consent form before any study procedures were undertaken. 


\section{Consent for publication}

No individual person's data are reported in this paper.

\section{Availability of data and materials}

The datasets analysed during the study are available from the corresponding author on reasonable request.

\section{Competing interests}

IMF is an independent consultant contracted to ENDS and tobacco product manufacturers to provide scientific and regulatory support for clinical and behavioral studies. RGNS is an independent consultant who provides statistical support to ENDS manufacturers. KG is an employee of, and WM is the President of, McKinney Regulatory Science Advisors, LLC who are contracted to provide scientific and regulatory support to ENDS and tobacco product manufacturers.

\section{Funding}

This study was sponsored by BIDI Vapor, LLC. This sponsor company had no involvement in the design or execution of the study other than to provide BIDI ${ }^{\circledR}$ Stick and JUUL ENDS, and further had no involvement in either the analysis or the reporting of study data.

\section{Authors' contributions}

IF wrote the manuscript and interpreted the study findings. KG and WM contributed to study conduct and were major contributors to manuscript writing. RGNS performed all statistical analyses presented in the manuscript. All authors read and approved the final manuscript.

\section{Acknowledgements}

The authors gratefully acknowledge the support of MTZ Clinical Research Sp. Z.o.o. (Warsaw, Poland) who conducted the study. The authors also with to thank Azim Chowdhury and Neelam Gill (Keller and Heckman LLP, Washington DC, USA) who contributed to the execution of the study.

\section{References}

1. World Health Organization. Tobacco 2021 [Available from: https://www.who.int/news-room/factsheets/detail/tobacco.

2. Institute of Medicine. Clearing the Smoke - Assessing the Science Base for Tobacco Harm Reduction. Washington. D.C.: The National Academies Press; 2001.

3. Perfetti T, Rodgman A. The Complexity of Tobacco and Tobacco Smoke. . Beiträge zur Tabakforschung International. 2011;24:17.

4. Stratton K, Shetty P, Wallace R, Bondurant S. Clearing the smoke: the science base for tobacco harm reductionexecutive summary. Tob Control. 2001;10(2):189-95.

5. Food and Drug Administration. Harmful and Potentially Harmful Constituents in Tobacco Products and Tobacco Smoke; Established List. Docket No. FDA-2012-N-0143. Federal Register. 2012;77(64). 
6. US Department of Health and Human Services. The Health Consequences of Smoking: 50 Years of Progress: a Report of the Surgeon General. Atlanta: Department of Health and Human Services, Centers for Disease Control and Prevention, National Center for Chronic Disease Prevention and Health Promotion, Office on Smoking and Health; 2014.

7. Babb S, Malarcher A, Schauer G, Asman K, Jamal A. Quitting Smoking Among Adults - United States, 2000-2015. MMWR Morb Mortal Wkly Rep. 2017;65(52):1457-64.

8. Russell MA. Low-tar medium-nicotine cigarettes: a new approach to safer smoking. Br Med J. 1976;1(6023):1430-3.

9. Public Health England. Evidence review of e-cigarettes and heated tobacco products 2018. A report commissioned by Public Health England. London: PHE Publications; 2018.

10. Hatsukami DK, Carroll DM. Tobacco harm reduction: Past history, current controversies and a proposed approach for the future. Prev Med. 2020;140:106099.

11. Royal College of Physicians. Nicotine without Smoke. Tobacco Harm Reduction. A Report by the Tobacco Advisory Group of the Royal College of Physicians. London: Royal College of Physicians; 2016.

12. Breland A, Soule E, Lopez A, Ramôa C, El-Hellani A, Eissenberg T. Electronic cigarettes: what are they and what do they do? Ann N Y Acad Sci. 2017;1394(1):5-30.

13. Voos N, Goniewicz ML, Eissenberg T. What is the nicotine delivery profile of electronic cigarettes? Expert Opin Drug Deliv. 2019;16(11):1193-203.

14. National Academies of Sciences Engineering and Medicine. Public Health Consequences of E-Cigarettes. Washington (DC): National Academies Press; 2018.

15. Margham J, McAdam K, Forster M, Liu C, Wright C, Mariner D, et al. Chemical Composition of Aerosol from an ECigarette: A Quantitative Comparison with Cigarette Smoke. Chem Res Toxicol. 2016;29(10):1662-78. doi: 10.021/acs.chemrestox.6b00188. Epub 2016 Sep 18.

16. Theron AJ, Feldman C, Richards GA, Tintinger GR, Anderson R. Electronic cigarettes: where to from here? J Thorac Dis. 2019;11(12):5572-85. doi: 10.21037/jtd.2019.11.82.

17. Cohen G, Goldenson NI, Bailey P, Chan S, Shiffman S. Changes in Biomarkers of Cigarette Smoke Exposure After 6 Days of Switching Exclusively or Partially to Use of the JUUL System with Two Nicotine Concentrations: A Randomized Controlled Confinement Study in Adult Smokers. Nicotine Tob Res. 2021;23(10):2153-61.

18. Goniewicz ML, Smith DM, Edwards KC, Blount BC, Caldwell KL, Feng J, et al. Comparison of Nicotine and Toxicant Exposure in Users of Electronic Cigarettes and Combustible Cigarettes. JAMA Netw Open. 2018;1(8):e185937.

19. McEwan M, Gale N, Ebajemito JK, Camacho OM, Hardie G, Proctor CJ, et al. A randomized controlled study in healthy participants to explore the exposure continuum when smokers switch to a tobacco heating product or an Ecigarette relative to cessation. Toxicol Rep. 2021;8:994-1001.(doi):10.1016/j.toxrep.2021.05.003. eCollection .

20. Morris P, McDermott S, Chapman F, Verron T, Cahours X, Stevenson M, et al. Reductions in biomarkers of exposure to selected harmful and potentially harmful constituents following exclusive and partial switching from combustible cigarettes to myblu $\left(^{(T M}\right)$ electronic nicotine delivery systems (ENDS). Intern Emerg Med. 2021;26(10):02102813.

Page $11 / 18$ 
21. Shahab L, Goniewicz ML, Blount BC, Brown J, McNeill A, Alwis KU, et al. Nicotine, Carcinogen, and Toxin Exposure in Long-Term E-Cigarette and Nicotine Replacement Therapy Users: A Cross-sectional Study. Ann Intern Med. 2017;166(6):390-400.

22. Smith DM, Shahab L, Blount BC, Gawron M, Kosminder L, Sobczak A, et al. Differences in Exposure to Nicotine, Tobacco-Specific Nitrosamines, and Volatile Organic Compounds among Electronic Cigarette Users, Tobacco Smokers, and Dual Users from Three Countries. Toxics. 2020;8(4):88. doi: 10.3390/toxics8040088.

23. Hartmann-Boyce J, McRobbie H, Butler AR, Lindson N, Bullen C, Begh R, et al. Electronic cigarettes for smoking cessation. Cochrane Database Syst Rev. 2021;9(9):CD010216. doi: 10.1002/14651858.CD010216.pub6.

24. Levy DT, Yuan Z, Luo Y, Abrams DB. The Relationship of E-Cigarette Use to Cigarette Quit Attempts and Cessation: Insights From a Large, Nationally Representative U.S. Survey. Nicotine Tob Res. 2018;20(8):931-9.

25. Berry KM, Reynolds LM, Collins JM, Siegel MB, Fetterman JL, Hamburg NM, et al. E-cigarette initiation and associated changes in smoking cessation and reduction: the Population Assessment of Tobacco and Health Study, 2013-2015. Tob Control. 2019;28(1):42-9.

26. Goldenson NI, Fearon IM, Buchhalter AR, Henningfield JE. An Open-Label, Randomized, Controlled, Crossover Study to Assess Nicotine Pharmacokinetics and Subjective Effects of the JUUL System with Three Nicotine Concentrations Relative to Combustible Cigarettes in Adult Smokers. Nicotine Tob Res. 2021;23(6):947-55. doi: 10.1093/ntr/ntab001.

27. Hajek P, Pittaccio K, Pesola F, Myers Smith K, Phillips-Waller A, Przulj D. Nicotine delivery and users' reactions to Juul compared with cigarettes and other e-cigarette products. Addiction. 2020;115(6):1141-8.

28. Phillips-Waller A, Przulj D, Smith KM, Pesola F, Hajek P. Nicotine delivery and user reactions to Juul EU (20 $\mathrm{mg} / \mathrm{ml}$ ) compared with Juul US (59 mg/ml), cigarettes and other e-cigarette products. Psychopharmacology (Berl). 2021;238(3):825-31.

29. Gottlieb S, Zeller M. A Nicotine-Focused Framework for Public Health. N Engl J Med. 2017;377(12):1111-4.

30. Hansson A, Rasmussen T, Kraiczi H. Single-Dose and Multiple-Dose Pharmacokinetics of Nicotine 6 mg Gum. Nicotine Tob Res. 2017;19(4):477-83.

31. Hansson A, Rasmussen T, Perfekt R, Hall E, Kraiczi H. Effect of nicotine 6 mg gum on urges to smoke, a randomized clinical trial. BMC Pharmacol Toxicol. 2019;20(1):69.

32. Lindson N, Chepkin SC, Ye W, Fanshawe TR, Bullen C, Hartmann-Boyce J. Different doses, durations and modes of delivery of nicotine replacement therapy for smoking cessation. Cochrane Database Syst Rev. 2019;4(4):Cd013308.

33. Tobacco Use and Dependence Guideline Panel. Tobacco Use and Dependence Guideline Panel. Treating Tobacco Use and Dependence: 2008 Update. Rockville (MD): ; 2008 May. Available from: https://www.ncbi.nlm.nih.gov/books/NBK63952/. Rockville, MS: US Department of Health and Human Services; 2008.

34. Voos N, Kaiser L, Mahoney MC, Bradizza CM, Kozlowski LT, Benowitz NL, et al. Randomized within-subject trial to evaluate smokers' initial perceptions, subjective effects and nicotine delivery across six vaporized nicotine products. Addiction. 2019;114(7):1236-48. doi: 10.111/add.14602. Epub 2019 Apr 25. 
35. Cobb CO, Foulds J, Yen MS, Veldheer S, Lopez AA, Yingst JM, et al. Effect of an electronic nicotine delivery system with 0,8 , or $36 \mathrm{mg} / \mathrm{mL}$ liquid nicotine versus a cigarette substitute on tobacco-related toxicant exposure: a four-arm, parallel-group, randomised, controlled trial. Lancet Respir Med. 2021;9(8):840-50. doi: 10.1016/S2213600(21)00022-9. Epub 2021 Apr 12.

36. Hiler M, Breland A, Spindle T, Maloney S, Lipato T, Karaoghlanian N, et al. Electronic cigarette user plasma nicotine concentration, puff topography, heart rate, and subjective effects: Influence of liquid nicotine concentration and user experience. Exp Clin Psychopharmacol. 2017;25(5):380-92. doi: 10.1037/pha0000140.

37. Fearon IM, Eldridge AC, Gale N, McEwan M, Stiles MF, Round EK. Nicotine pharmacokinetics of electronic cigarettes: A review of the literature. Regul Toxicol Pharmacol. 2018;100:25-34.(doi):10.1016/j.yrtph.2018.09.004. Epub Sep 8.

38. Jacobson K, Martinez J, Larroque S, Jones IW, Paschke T. Nicotine pharmacokinetics of electronic cigarettes: A pooled data analysis from the literature. Toxicol Rep. 2021;8:84-95.(doi):10.1016/j.toxrep.2020.12.016. eCollection 1.

39. Nides MA, Leischow SJ, Bhatter M, Simmons M. Nicotine blood levels and short-term smoking reduction with an electronic nicotine delivery system. Am J Health Behav. 2014;38(2):265-74. doi: 10.5993/AJHB.38.2.12.

40. Fagerström K. Determinants of tobacco use and renaming the FTND to the Fagerstrom Test for Cigarette Dependence. Nicotine Tob Res. 2012;14(1):75-8.

41. Hatsukami DK, Zhang Y, O'Connor RJ, Severson HH. Subjective responses to oral tobacco products: scale validation. Nicotine Tob Res. 2013;15(7):1259-64.

42. Ramôa CP, Hiler MM, Spindle TR, Lopez AA, Karaoghlanian N, Lipato T, et al. Electronic cigarette nicotine delivery can exceed that of combustible cigarettes: a preliminary report. Tob Control. 2016;25(e1):e6-9.

43. Food and Drug Administration. Technical Project Lead Review of IQOS Silver SPring, MD2019 [Available from: https://www.fda.gov/media/124247/download.

44. Do EK, O'Connor K, Perks SN, Soule EK, Eissenberg T. E-cigarette device and liquid characteristics and E-cigarette dependence: A pilot study of pod-based and disposable E-cigarette users. Addict Behav. 2021;124(1):107117.

45. Liu G, Wasserman E, Kong L, Foulds J. A comparison of nicotine dependence among exclusive E-cigarette and cigarette users in the PATH study. Prev Med. 2017;104:86-91.

46. Voos N, Smith D, Kaiser L, Mahoney MC, Bradizza CM, Kozlowski LT, et al. Effect of e-cigarette flavors on nicotine delivery and puffing topography: results from a randomized clinical trial of daily smokers. Psychopharmacology (Berl). 2020;237(2):491-502.

47. Goldenson NI, Buchhalter AR, Augustson EM, Rubinstein ML, Henningfield JE. Abuse liability assessment of the JUUL system in four flavors relative to combustible cigarette, nicotine gum and a comparator electronic nicotine delivery system among adult smokers. Drug Alcohol Depend. 2020;217:108395.

48. St Helen G, Dempsey DA, Havel CM, Jacob P, 3rd, Benowitz NL. Impact of e-liquid flavors on nicotine intake and pharmacology of e-cigarettes. Drug Alcohol Depend. 2017;178:391-8.

49. Stiles MF, Campbell LR, Graff DW, Jones BA, Fant RV, Henningfield JE. Pharmacodynamic and pharmacokinetic assessment of electronic cigarettes, combustible cigarettes, and nicotine gum: implications for abuse liability. 
Psychopharmacology (Berl). 2017;234(17):2643-55.

50. Stiles MF, Campbell LR, Jin T, Graff DW, Fant RV, Henningfield JE. Assessment of the abuse liability of three menthol Vuse Solo electronic cigarettes relative to combustible cigarettes and nicotine gum. Psychopharmacology (Berl). 2018;235(7):2077-86.

51. Abrams DB, Glasser AM, Villanti AC, Pearson JL, Rose S, Niaura RS. Managing nicotine without smoke to save lives now: Evidence for harm minimization. Prev Med. 2018;117:88-97.

52. Tucker MR, Laugesen M, Bullen C, Grace RC. Predicting short-term uptake of electronic cigarettes: effects of nicotine, subjective effects, and simulated demand. Nicotine and Tobacco Research. 2018;20(10):1265-71.

53. Higgins ST, Redner R, Arger CA, Kurti AN, Priest JS, Bunn JY. Use of higher-nicotine/tar-yield (regular full-flavor) cigarettes is associated with nicotine dependence and smoking during pregnancy among U.S. women. Prev Med. 2017; 104:57-62.

54. Kuiper N, Coats EM, Crawford TN, Gammon DG, Loomis B, Watson CH, et al. Trends in Manufacturer-Reported Nicotine Yields in Cigarettes Sold in the United States, 2013-2016. Prev Chronic Dis. 2020;17:E148.

55. Goldenson NI, Buchhalter AR, Augustson EM, Rubinstein ML, Van Hoof D, Henningfield JE. Abuse liability assessment of the JUUL system in two nicotine concentrations compared to combustible cigarette, nicotine gum and comparator electronic nicotine delivery system. Drug Alcohol Depend. 2020;217:108441.

56. Farsalinos KE, Spyrou A, Stefopoulos C, Tsimopoulou K, Kourkoveli P, Tsiapras D, et al. Nicotine absorption from electronic cigarette use: comparison between experienced consumers (vapers) and naïve users (smokers). Sci Rep. 2015;5:11269.

57. Hajek P, Goniewicz ML, Phillips A, Myers Smith K, West O, McRobbie H. Nicotine intake from electronic cigarettes on initial use and after 4 weeks of regular use. Nicotine Tob Res. 2015;17(2):175-9.

\section{Tables}

Table 1. Nicotine Pharmacokinetic Parameters for BIDI Stick ${ }^{\circledR}$ ENDS and Comparator Products. $\mathrm{N}=$ 17-18 in each case. UB, usual brand; SD, standard deviation; VT, Virginia Tobacco; min, minimum; max, maximum. 


\begin{tabular}{|c|c|c|c|c|c|c|c|c|}
\hline & \begin{tabular}{|c|} 
UB \\
Cigarette
\end{tabular} & $\begin{array}{c}\text { BIDI }^{\circledR} \text { Stick } \\
\text { Arctic }\end{array}$ & $\begin{array}{l}\text { BIDI }^{\circledR} \text { Stick } \\
\text { Classic }\end{array}$ & $\begin{array}{c}\text { BIDI }^{\circledR} \text { Stick } \\
\text { Regal }\end{array}$ & $\begin{array}{l}\text { BIDI }{ }^{\circledR} \text { Stick } \\
\text { Solar }\end{array}$ & $\begin{array}{l}\text { BIDI }^{\circledR} \text { Stick } \\
\text { Winter }\end{array}$ & $\begin{array}{c}\text { BIDI }^{\circledR} \text { Stick } \\
\text { Zest }\end{array}$ & JUUL VT \\
\hline $\begin{array}{|ll|}\mathrm{C}_{\max } & 0-120 \\
(\mathrm{ng} / \mathrm{mL}) & \\
\text { Mean (SD) } \\
\text { Geometric } \\
\text { mean (SD) } \\
\text { Median } \\
\text { Min, max }\end{array}$ & $\left|\begin{array}{c}16.2(9.17) \\
14.0(1.74) \\
13.9 \\
4.7,40.6\end{array}\right|$ & $\begin{array}{c}16.8(9.71) \\
13.5(2.18) \\
16.6 \\
1.4,36.8\end{array}$ & $\begin{array}{c}17.6(9.00) \\
15.5(1.68) \\
13.3 \\
7.1,33.9\end{array}$ & $\begin{array}{c}15.6(8.72) \\
13.4(1.80) \\
13.7 \\
3.8,37.0\end{array}$ & $\begin{array}{c}16.0(11.73) \\
12.6(2.07) \\
11.1 \\
2.6,41.2\end{array}$ & $\begin{array}{c}15.3(9.90) \\
13.1(1.76) \\
12.0 \\
4.4 \text { to } 44.6\end{array}$ & $\begin{array}{c}17.2(10.30) \\
14.7(1.77) \\
11.6 \\
5.4 \text { to } 42.7\end{array}$ & \begin{tabular}{|c}
$6.8(4.13)$ \\
$5.7(1.89)$ \\
5.7 \\
1.8 to \\
14.78
\end{tabular} \\
\hline $\begin{array}{l}\mathrm{AUC}_{0-120} \\
(\mathrm{~min} * \mathrm{ng} / \mathrm{mL}) \\
\text { Mean (SD) } \\
\text { Geometric } \\
\text { mean (SD) } \\
\text { Median } \\
\text { Min, max }\end{array}$ & $\begin{array}{c}742.2 \\
(330.05) \\
671.8 \\
(1.61) \\
665.5 \\
233.4 \\
1448.4\end{array}$ & \begin{tabular}{|c}
624.0 \\
$(217.00)$ \\
$589.0(1.43)$ \\
610.9 \\
$321.1,1118.8$
\end{tabular} & $\mid \begin{array}{c}618.0(290.33) \\
565.0(1.54) \\
607.2 \\
251.5,1491.0\end{array}$ & $\begin{array}{c}561.12 \\
(351.77) \\
\\
384.3(3.45) \\
590.0 \\
7.7,1412.1\end{array}$ & $\begin{array}{c}628.6 \\
(412.57) \\
\\
455.1(3.20) \\
532.9 \\
7.4,1679.2\end{array}$ & $\begin{array}{c}587.2(334.23) \\
484.4(2.04) \\
530.9 \\
75.2,1206.6\end{array}$ & $\begin{array}{c}635.4 \\
(288.25) \\
\\
572.6(1.65) \\
584.1 \\
146.3 \\
1312.7\end{array}$ & $\begin{array}{c}293.6 \\
(173.39) \\
202.1 \\
(3.55) \\
284.7 \\
\\
4.5,588.2\end{array}$ \\
\hline \begin{tabular}{|ll}
$\mathrm{T}_{\max }$ & $0-120$ \\
$($ minutes) & \\
Mean (SD) & \\
Median & \\
Min, max & \\
\end{tabular} & $\begin{array}{c}6.7(2.74) \\
6 \\
3,15\end{array}$ & $\begin{array}{c}6.2(1.39) \\
7 \\
5,10\end{array}$ & $\begin{array}{c}6.11 .41) \\
5 \\
5,10\end{array}$ & $\begin{array}{c}6.0(1.58) \\
5 \\
3,10\end{array}$ & $\begin{array}{c}6.1(1.58) \\
7 \\
3,10\end{array}$ & $\begin{array}{c}6.0(1.41) \\
5 \\
5,10\end{array}$ & $\begin{array}{c}6.8(2.51) \\
7 \\
5,15\end{array}$ & $\begin{array}{c}5.9(1.73) \\
5 \\
3,10\end{array}$ \\
\hline \begin{tabular}{|l|}
$\mathrm{C}_{\max }$ \\
$(\mathrm{ng} / \mathrm{ml})$ \\
Mean (SD) \\
\\
Geometric \\
mean (SD) \\
Median \\
Min, max
\end{tabular} & \begin{tabular}{|c|}
$11.0(5.30)$ \\
10.04 \\
$(1.53)$ \\
9.3 \\
$4.9,25.6$ \\
\end{tabular} & \begin{tabular}{|c|}
$23.7(12.67)$ \\
$18.61(2.09)$ \\
\\
28.8 \\
$3.5,38.4$ \\
\end{tabular} & $\begin{array}{l}19.6(10.43) \\
17.32(1.67)\end{array}$ & $\begin{array}{l}15.9(13.29) \\
12.44(2.54)\end{array}$ & $\begin{array}{l}20.0(11.73) \\
16.96(1.82)\end{array}$ & $\begin{array}{l}19.6(14.67) \\
16.86(2.03)\end{array}$ & $\begin{array}{c}19.4(10.21) \\
17.56(1.78) \\
16.3 \\
5.3,40.6\end{array}$ & $\begin{array}{c}11.3 \\
(10.85) \\
8.52(2.37) \\
\\
6.8 \\
1.7,41.2\end{array}$ \\
\hline
\end{tabular}

Table 2. Statistical Comparison of Nicotine Pharmacokinetic Parameters. $\mathrm{N}=10-17$ in aBack-transformed (exponentiated) linear mixed model parameter estimates used to create 90\% ( geometric least squares means between study products. b Odds ratios 90\% CIs. Statistical sig] concluded if the CIs do not contain 1.00. UB, usual brand; LS, least square; CI, confidence interval. Vi were significantly different are in bold type. 


\begin{tabular}{|c|c|c|c|c|c|c|c|}
\hline & $\begin{array}{l}\text { BIDI }^{\circledR} \text { Stick } \\
\text { Arctic }\end{array}$ & $\begin{array}{l}\text { BIDI }^{\circledR} \text { Stick } \\
\text { Classic }\end{array}$ & $\begin{array}{l}\text { BIDI }{ }^{\circledR} \text { Stick } \\
\text { Regal }\end{array}$ & $\begin{array}{l}\text { BIDI }^{\circledR} \text { Stick } \\
\text { Solar }\end{array}$ & $\begin{array}{l}\text { BIDI }^{\circledR} \text { Stick } \\
\text { Winter }\end{array}$ & $\begin{array}{l}\text { BIDI }^{\circledR} \text { Stick } \\
\text { Zest }\end{array}$ & JUUL VT \\
\hline \multicolumn{8}{|l|}{$\begin{array}{l}C_{\max } 0-120 \text { LS Means }(90 \% \\
C I)^{a}\end{array}$} \\
\hline $\begin{array}{l}\text { BIDI Stick }^{\circledR} \text { Classic } \\
\text { ENDS }\end{array}$ & $\begin{array}{c}0.89 \\
(0.71,1.12)\end{array}$ & -- & -- & -- & -- & -- & -- \\
\hline $\begin{array}{l}\text { BIDI Stick }^{\circledR} \text { Regal } \\
\text { ENDS }\end{array}$ & $\begin{array}{c}1.01 \\
(0.80,1.27)\end{array}$ & $\begin{array}{c}1.13 \\
(0.90,1.43)\end{array}$ & -- & -- & -- & -- & -- \\
\hline BIDI Stick $^{\circledR}$ Solar ENDS & $\begin{array}{c}1.07 \\
(0.85,1.35)\end{array}$ & $\begin{array}{c}1.20 \\
(0.95,1.51)\end{array}$ & $\begin{array}{c}1.06 \\
(0.84,1.33)\end{array}$ & -- & -- & -- & -- \\
\hline $\begin{array}{l}\text { BIDI Stick }^{\circledR} \text { Winter } \\
\text { ENDS }\end{array}$ & $\begin{array}{c}1.05 \\
(0.83,1.33)\end{array}$ & $\begin{array}{c}1.18 \\
(0.93,1.49)\end{array}$ & $\begin{array}{c}1.04 \\
(0.82,1.31)\end{array}$ & $\begin{array}{c}0.98 \\
(0.78,1.24)\end{array}$ & -- & -- & -- \\
\hline BIDI Stick $^{\circledR}$ Zest ENDS & $\begin{array}{c}0.94 \\
(0.75,1.19)\end{array}$ & $\begin{array}{c}1.06 \\
(0.84,1.33)\end{array}$ & $\begin{array}{c}0.93 \\
(0.74,1.18)\end{array}$ & $\begin{array}{c}0.88 \\
(0.70,1.11)\end{array}$ & $\begin{array}{c}0.89 \\
(0.71,1.13)\end{array}$ & -- & -- \\
\hline JUUL VT ENDS & $\begin{array}{c}2.44 \\
(1.93,3.08)\end{array}$ & $\begin{array}{c}2.74 \\
(2.17,3.45)\end{array}$ & $\begin{array}{c}2.42 \\
(1.91,3.05)\end{array}$ & $\begin{array}{c}2.28 \\
(1.81,2.88)\end{array}$ & $\begin{array}{c}2.32 \\
(1.84,2.93)\end{array}$ & $\begin{array}{c}2.59 \\
(2.06,3.27)\end{array}$ & -- \\
\hline UB Cigarette & $\begin{array}{c}1.00 \\
(0.72,1.38)\end{array}$ & $\begin{array}{c}1.12 \\
(0.81,1.55)\end{array}$ & $\begin{array}{c}0.99 \\
(0.71,1.37)\end{array}$ & $\begin{array}{c}0.93 \\
(0.67,1.29)\end{array}$ & $\begin{array}{c}0.95 \\
(0.68,1.32)\end{array}$ & $\begin{array}{c}1.06 \\
(0.77,1.47)\end{array}$ & $\begin{array}{c}0.41 \\
(0.30,0.57)\end{array}$ \\
\hline \multicolumn{8}{|l|}{$\begin{array}{l}\mathrm{AUC}_{0-120} \text { LS Means } 90 \% \\
(\mathrm{CI})^{\mathrm{a}}\end{array}$} \\
\hline $\begin{array}{l}\text { BIDI } \text { Stick }^{\circledR} \quad \text { Classic } \\
\text { ENDS }\end{array}$ & $\begin{array}{c}0.92 \\
(0.73,1.16)\end{array}$ & -- & -- & -- & -- & -- & -- \\
\hline $\begin{array}{lll}\text { BIDI } & \text { Stick }^{\circledR} & \text { Regal } \\
\text { ENDS } & & \end{array}$ & $\begin{array}{c}0.97 \\
(0.78,1.21)\end{array}$ & $\begin{array}{c}1.05 \\
(0.84,1.33)\end{array}$ & -- & -- & -- & -- & -- \\
\hline BIDI Stick $^{\circledR}$ Solar ENDS & $\begin{array}{c}0.96 \\
(0.78,1.19)\end{array}$ & $\begin{array}{c}1.04 \\
(0.83,1.32)\end{array}$ & $\begin{array}{c}0.99 \\
(0.79,1.24)\end{array}$ & -- & -- & -- & -- \\
\hline 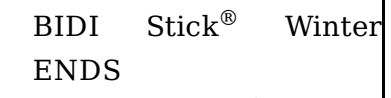 & $\begin{array}{c}1.04 \\
(0.84,1.29)\end{array}$ & $\begin{array}{c}1.13 \\
(0.89,1.42)\end{array}$ & $\begin{array}{c}1.07 \\
(0.86,1.33)\end{array}$ & $\begin{array}{c}1.08 \\
(0.87,1.34)\end{array}$ & -- & -- & -- \\
\hline $\begin{array}{lll}\text { B BIDI } & \text { Stick }^{\circledR} & \text { Zest } \\
\text { ENDS } & & \end{array}$ & $\begin{array}{c}0.94 \\
(0.75,1.17)\end{array}$ & $1.02(0.8,1.29)$ & $\begin{array}{c}0.96 \\
(0.77,1.21)\end{array}$ & $\begin{array}{c}0.97 \\
(0.78,1.22)\end{array}$ & $\begin{array}{c}0.90 \\
(0.72,1.13)\end{array}$ & -- & -- \\
\hline JUUL VT ENDS & $\begin{array}{c}1.86 \\
(1.47,2.35)\end{array}$ & $\begin{array}{c}2.02 \\
(1.58,2.58)\end{array}$ & $\begin{array}{c}1.91 \\
(1.51,2.43)\end{array}$ & $\begin{array}{c}1.93 \\
(1.53,2.45)\end{array}$ & $\begin{array}{c}1.79 \\
(1.41,2.27)\end{array}$ & $\begin{array}{c}1.98 \\
(1.56,2.52)\end{array}$ & -- \\
\hline UB Cigarette & $\begin{array}{c}0.81 \\
(0.66,0.99)\end{array}$ & $0.88(0.7,1.1)$ & $\begin{array}{c}0.83 \\
(0.68,1.03)\end{array}$ & $\begin{array}{c}0.84 \\
(0.68,1.04)\end{array}$ & $\begin{array}{c}0.78 \\
(0.63,0.96)\end{array}$ & $\begin{array}{c}0.86 \\
(0.7,1.07) \\
\end{array}$ & $\begin{array}{c}0.44 \\
(0.35,0.55)\end{array}$ \\
\hline \multicolumn{8}{|l|}{$\begin{array}{llll}\mathrm{T}_{\max } & 0-120 & \text { (Odds } & \text { Ratios } \\
90 \% & (\mathrm{CI})^{\mathrm{b}} & & \\
9\end{array}$} \\
\hline $\begin{array}{lll}\text { BIDI } & \text { Stick }^{\circledR} & \text { Classic } \\
\text { ENDS } & & \end{array}$ & $\begin{array}{c}0.79 \\
(0.25,2.42)\end{array}$ & -- & -- & -- & -- & -- & -- \\
\hline $\begin{array}{lll}\text { BIDI } & \text { Stick }^{\circledR} & \text { Regal } \\
\text { ENDS } & & \end{array}$ & $\begin{array}{c}0.70 \\
(0.23,2.16)\end{array}$ & $\begin{array}{c}0.89 \\
(0.29,2.76)\end{array}$ & -- & -- & -- & -- & -- \\
\hline BIDI Stick $^{\circledR}$ Solar ENDS & $\begin{array}{c}0.84 \\
(0.27,2.58)\end{array}$ & $\begin{array}{c}1.07 \\
(0.35,3.30)\end{array}$ & $\begin{array}{c}1.20 \\
(0.39,3.71)\end{array}$ & -- & -- & -- & -- \\
\hline $\begin{array}{lll}\text { BIDI } & \text { Stick }^{\circledR} & \text { Winter } \\
\text { ENDS } & & \end{array}$ & $\begin{array}{c}0.65 \\
(0.21,2.02)\end{array}$ & $\begin{array}{c}0.83 \\
(0.27,2.58)\end{array}$ & $\begin{array}{c}0.93 \\
(0.30,2.90)\end{array}$ & $\begin{array}{c}0.78 \\
(0.25,2.41)\end{array}$ & -- & -- & -- \\
\hline BIDI Stick $^{\circledR}$ Zest ENDS & $\begin{array}{c}1.40 \\
(0.46,4.29)\end{array}$ & $\begin{array}{c}1.79 \\
(0.58,5.49)\end{array}$ & $\begin{array}{c}2.01 \\
(0.65,6.19)\end{array}$ & $\begin{array}{c}1.67 \\
(0.54,5.13)\end{array}$ & $\begin{array}{c}2.15 \\
(0.70,6.65)\end{array}$ & -- & -- \\
\hline JUUL VT ENDS & $\begin{array}{c}0.59 \\
(0.19,1.82)\end{array}$ & $\begin{array}{c}0.75 \\
(0.24,2.33)\end{array}$ & $\begin{array}{c}0.84 \\
(0.27,2.62)\end{array}$ & $\begin{array}{c}0.70 \\
(0.23,2.18)\end{array}$ & $\begin{array}{c}0.90 \\
(0.29,2.81)\end{array}$ & $\begin{array}{c}0.42 \\
(0.13,1.30)\end{array}$ & -- \\
\hline UB Cigarette & $\begin{array}{c}1.08 \\
(0.36,3.27)\end{array}$ & $\begin{array}{c}1.38 \\
(0.45,4.19)\end{array}$ & $\begin{array}{c}1.54 \\
(0.51,4.71)\end{array}$ & $\begin{array}{c}1.29 \\
(0.42,3.91)\end{array}$ & $\begin{array}{c}1.66 \\
(0.54,5.06)\end{array}$ & $\begin{array}{c}0.77 \\
(0.26,2.32)\end{array}$ & $\begin{array}{c}1.84 \\
(0.60,5.65)\end{array}$ \\
\hline
\end{tabular}

Table 3. Product Evaluation Scale Scores. $\mathrm{N}=17-18$ in each case. Test products in the same row that do not share superscripts significantly differ $(p<0.05)$ based on a linear mixed model. Pairwise 
comparisons were tested from the omnibus linear mixed model. The enough nicotine individual item is a component of the 'relief' subscale. All items were answered on seven-point response scales from 1 ("not at all") to 7 ("extremely"). UB, usual brand; Min, minimum; max, maximum; VT, Virginia Tobacco; SD, standard deviation.

\begin{tabular}{|c|c|c|c|c|c|c|c|c|}
\hline & \begin{tabular}{|c|} 
UB \\
Cigarette
\end{tabular} & $\begin{array}{c}\text { BIDI }^{\circledR} \text { Stick } \\
\text { Arctic }\end{array}$ & $\begin{array}{l}\text { BIDI }^{\circledR} \text { Stick } \\
\text { Classic }\end{array}$ & $\begin{array}{c}\text { BIDI }^{\circledR} \text { Stick } \\
\text { Regal }\end{array}$ & $\begin{array}{l}\text { BIDI }^{\circledR} \text { Stick } \\
\text { Solar }\end{array}$ & $\begin{array}{c}\text { BIDI }^{\circledR} \text { Stick } \\
\text { Winter }\end{array}$ & \begin{tabular}{|c|} 
BIDI $^{\circledR}$ Stick \\
Zest
\end{tabular} & JUUL VT \\
\hline $\begin{array}{l}\text { Relief } \\
\text { Mean (SD) } \\
\text { Median } \\
\text { Min to max }\end{array}$ & $\begin{array}{c}4.67 \\
(1.13)^{\mathrm{a}} \\
4.70 \\
2.80 \text { to } \\
7.00\end{array}$ & $\begin{array}{c}4.44(1.19)^{\mathrm{a}} \\
4.60 \\
2.20 \text { to } 7.00\end{array}$ & $\begin{array}{l}4.36(1.13)^{\mathrm{a}} \\
4.60 \\
2.20 \text { to } 6.00\end{array}$ & $\begin{array}{l}4.66(1.25)^{\mathrm{a}} \\
\quad 4.80 \\
2.00 \text { to } 7.00\end{array}$ & $\begin{array}{c}4.65(1.17)^{\mathrm{a}} \\
4.80 \\
2.20 \text { to } 6.20\end{array}$ & $\begin{array}{l}4.15(1.10)^{\mathrm{a}} \\
\quad 4.00 \\
2.20 \text { to } 6.00\end{array}$ & $\begin{array}{c}4.61(1.29)^{\mathrm{a}} \\
4.60 \\
2.20 \text { to } 7.00\end{array}$ & $\begin{array}{c}4.24 \\
(1.18)^{\mathrm{a}} \\
4.20 \\
2.60 \text { to } \\
7.00\end{array}$ \\
\hline $\begin{array}{l}\text { Satisfaction } \\
\text { Mean (SD) } \\
\text { Median } \\
\text { Min to max }\end{array}$ & $\begin{array}{c}4.56 \\
(1.47)^{\mathrm{a}} \\
4.13 \\
2.25 \text { to } \\
7.00\end{array}$ & $\begin{array}{c}4.76(1.45)^{\mathrm{a}} \\
5.50 \\
2.50 \text { to } 7.00\end{array}$ & $\begin{array}{l}4.24(1.44)^{\mathrm{a}} \\
\quad 4.50 \\
1.00 \text { to } 6.00\end{array}$ & $\begin{array}{c}4.74(1.21)^{\mathrm{a}} \\
4.50 \\
2.25 \text { to } 7.00\end{array}$ & $\begin{array}{c}5.00(1.37)^{\mathrm{a}} \\
5.00 \\
2.25 \text { to } 7.00\end{array}$ & $\begin{array}{l}4.50(1.77)^{\mathrm{a}} \\
\quad 5.25 \\
1.00 \text { to } 6.75\end{array}$ & $\begin{array}{c}4.97(1.22)^{\mathrm{a}} \\
5.00 \\
2.00 \text { to } 7.00\end{array}$ & $\begin{array}{c}4.22 \\
(1.37)^{\mathrm{a}} \\
4.00 \\
2.00 \text { to } \\
6.75\end{array}$ \\
\hline $\begin{array}{l}\text { Psychological } \\
\text { Reward } \\
\text { Mean (SD) } \\
\text { Median } \\
\text { Min to max }\end{array}$ & $\begin{array}{c}4.54 \\
(1.12)^{\mathrm{b}} \\
4.60 \\
2.80 \text { to } \\
7.00\end{array}$ & $\begin{array}{c}4.06(1.34)^{\mathrm{ab}} \\
4.00 \\
1.80 \text { to } 6.00\end{array}$ & $\begin{array}{c}3.98(1.48)^{\mathrm{ab}} \\
4.00 \\
1.00 \text { to } 7.00\end{array}$ & $\begin{array}{c}4.06(1.31)^{\mathrm{ab}} \\
4.20 \\
2.00 \text { to } 7.00\end{array}$ & $\begin{array}{c}4.06(1.03)^{\mathrm{ab}} \\
4.20 \\
2.20 \text { to } 5.40\end{array}$ & $\begin{array}{l}3.53(1.43)^{\mathrm{a}} \\
\quad 4.00 \\
1.00 \text { to } 5.40\end{array}$ & $\mid \begin{array}{c}4.05(1.47)^{\mathrm{ab}} \\
4.00 \\
1.00 \text { to } 7.00\end{array}$ & $\begin{array}{c}4.04 \\
(1.27)^{\mathrm{ab}} \\
3.60 \\
2.00 \text { to } \\
6.80\end{array}$ \\
\hline $\begin{array}{l}\text { Aversion } \\
\text { Mean (SD) } \\
\text { Median } \\
\text { Min to max }\end{array}$ & $\begin{array}{c}2.24 \\
(1.49)^{\mathrm{a}} \\
1.88 \\
1.00 \text { to } \\
7.00\end{array}$ & $\begin{array}{c}2.10(0.94)^{\mathrm{a}} \\
2.00 \\
1.00 \text { to } 4.00\end{array}$ & $\begin{array}{l}2.13(1.10)^{\mathrm{a}} \\
\quad 1.75 \\
1.00 \text { to } 4.50\end{array}$ & $\begin{array}{c}2.49(1.17)^{\mathrm{a}} \\
2.50 \\
1.00 \text { to } 5.00\end{array}$ & $\begin{array}{c}1.96(1.12)^{\mathrm{a}} \\
1.50 \\
1.00 \text { to } 4.00\end{array}$ & $\begin{array}{c}2.03(1.15)^{\mathrm{a}} \\
1.50 \\
1.00 \text { to } 4.00\end{array}$ & $\begin{array}{c}2.49(1.52)^{\mathrm{a}} \\
2.25 \\
1.00 \text { to } 5.00\end{array}$ & $\begin{array}{c}2.12 \\
(1.03)^{\mathrm{a}} \\
2.00 \\
1.00 \text { to } \\
4.00\end{array}$ \\
\hline $\begin{array}{l}\text { Was it Enough } \\
\text { Nicotine Item } \\
\text { Mean (SD) } \\
\text { Median } \\
\text { Min to max }\end{array}$ & $\begin{array}{c}5.39 \\
(1.29)^{\mathrm{d}} \\
5.00 \\
3.00 \text { to } \\
7.00 \\
\end{array}$ & $\begin{array}{c}4.47(1.62)^{\mathrm{abc}} \\
4.00 \\
1.00 \text { to } 7.00\end{array}$ & $\begin{array}{c}4.76(1.52)^{\mathrm{abcd}} \\
5.00 \\
1.00 \text { to } 7.00\end{array}$ & $\begin{array}{c}5.12(1.54)^{\mathrm{ad}} \\
5.00 \\
2.00 \text { to } 7.00\end{array}$ & $\begin{array}{c}5.00(1.27)^{\mathrm{abc}} \\
5.00 \\
3.00 \text { to } 7.00 \\
\end{array}$ & $\mid \begin{array}{c}4.65(1.54)^{\mathrm{abcd}} \\
5.00 \\
1.00 \text { to } 7.00\end{array}$ & $\begin{array}{c}4.88 \\
(1.58)^{\mathrm{abd}} \\
5.00 \\
1.00 \text { to } 7.00\end{array}$ & $\begin{array}{c}4.06 \\
(1.85)^{\mathrm{c}} \\
4.00 \\
1.00 \text { to } \\
7.00 \\
\end{array}$ \\
\hline
\end{tabular}

Supplementary Table 1. Demographic details for study subjects. Values are presented as means \pm

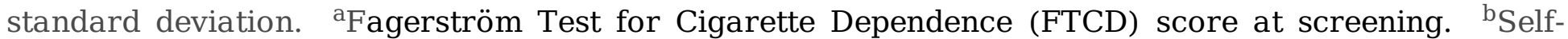
reported daily cigarette consumption at screening. Abbreviation: BMI, body mass index; Min, minimum; max, maximum. 


\begin{tabular}{|l|c|c|}
\hline \multicolumn{1}{|c|}{ Characteristic } & Metric & Values \\
\hline Age (years) & $\begin{array}{c}\text { Mean (SD) } \\
\text { Min, max }\end{array}$ & $\begin{array}{c}39.2(9.21) \\
26,55\end{array}$ \\
\hline Sex (male:female) & $\mathrm{N}(\%): \mathrm{N}(\%)$ & $11(61.1): 7(38.9)$ \\
\hline $\begin{array}{l}\text { Race } \\
\text { Caucasian }\end{array}$ & $\mathrm{N}(\%)$ & $18(100)$ \\
\hline Weight (males; kg) & Mean (SD) & $79.3(4.22)$ \\
\hline Weight (females; kg) & Mean (SD) & $66.6(11.64)$ \\
\hline BMI (kg/m $\left.{ }^{2}\right)$ & Mean (SD) & $24.9(3.09)$ \\
\hline FTCD score & Mean (SD) & $5.8(1.66)$ \\
\hline Cigarette consumption ${ }^{\mathrm{a}}$ & Mean (SD) & $16.6(4.82)$ \\
& Min, max & 10,30 \\
\hline Time since smoking initiation (years) & Mean (SD) & $19.3(7.66)$ \\
\hline
\end{tabular}

\section{Figures}

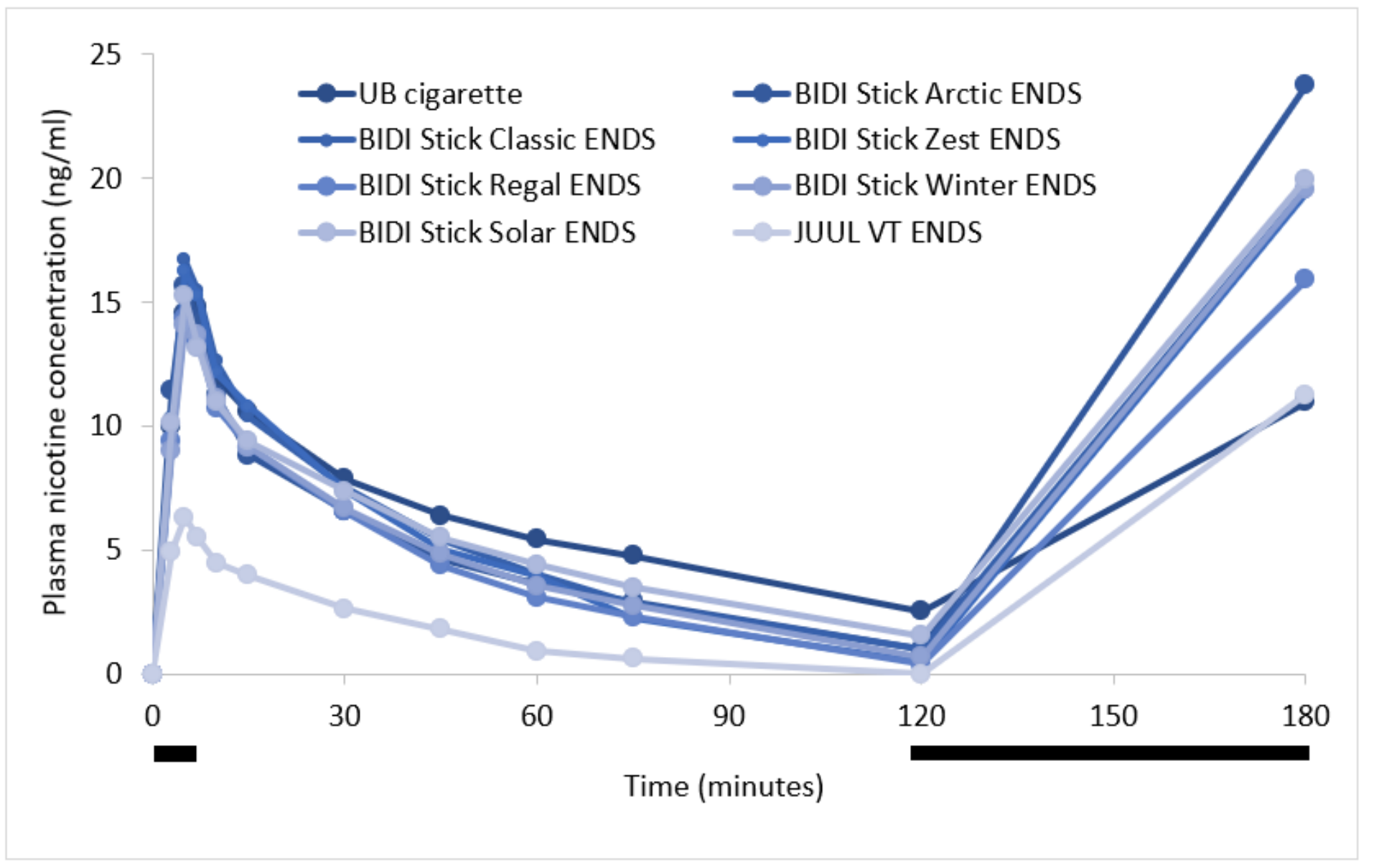

Figure 1

Mean Baseline Adjusted Plasma Nicotine Concentration by Time. $\mathrm{N}=1718$ in each case. Solid black bars below the plot indicate the defined ( 0 - 5 minutes) and ad libitum (120 - 180 minutes) puffing sessions. Errors bars have been omitted for clarity; for variability estimates refer to Table 1. UB, usual brand; VT, Virginia Tobacco. 